\title{
High Quality Oxygen Measurements from Profiling Floats: A Promising New Technique
}

\author{
ARne KörtZinger And Jens Schimanski \\ Marine Biogeochemistry Department, Leibniz-Institut für Meereswissenschaften, Kiel, Germany \\ UwE SEND \\ Physical Oceanography Department, Leibniz-Institut für Meereswissenschaften, Kiel, Germany
}

(Manuscript received 6 April 2004, in final form 12 July 2004)

\begin{abstract}
Two state-of-the-art profiling floats were equipped with novel optode-based oceanographic oxygen sensors. Both floats were simultaneously deployed in the central Labrador Sea gyre on 7 September 2003. They drift at a depth of $800 \mathrm{db}$ and perform weekly profiles of temperature, salinity, and oxygen in the upper 2000 $\mathrm{m}$ of the water column. The initial results from the first 6 months of operation are presented. Data are compared with a small hydrographic oxygen survey of the deployment site. They are further examined for measurement quality, including precision, accuracy, and drift aspects. The first 28 profiles obtained are of high quality and show no detectable sensor drift. A method of long-term drift control is described and a few suggestions for the operation protocol are provided.
\end{abstract}

\section{Introduction}

Careful analyses have documented significant changes of temperature (Levitus et al. 2000) and salinity (Curry et al. 2003) in the surface (and deep) ocean. Such changes in the physical state of the "anthropocene" ocean are bound to cause changes in the chemical and biological state and functioning of the marine system. Oxygen is a component that will respond to both physical changes (temperature and salinity dependence of oxygen solubility, ventilation) as well as biological changes (e.g., different temperature dependence of photosynthesis and respiration, effect of stratification changes on vertical nutrient supply, and utilization efficiency) and therefore can potentially be used as a sensitive indicator of environmental change in the ocean (Joos et al. 2003). Recent measurements and model studies have consistently identified a decreasing trend in the concentration of dissolved $\mathrm{O}_{2}$ in the ocean over the last several decades (e.g., Matear et al. 2000; Keeling and Garcia 2002; Bopp et al. 2002), which have important implications for our understanding of anthropogenic climate change.

Oxygen has a century-long history of use as a tool for

Corresponding author address: Arne Körtzinger, Marine Biogeochemistry Dept., Leibniz-Institut für Meereswissenschaften, 24105 Kiel, Germany.

E-mail: akoertzinger@ifm-geomar.de understanding ocean circulation. In fact, it was the first true chemical measurement to be performed regularly with temperature and salinity. Until today, this parameter has retained its importance and we can look back on long-standing records of oxygen concentrations in the ocean - a fact that has been possible only due to the virtually unchanged survival of an elegant and reliable chemical method (Winkler 1888). Attempts to complement this classical wet-chemical method with a sensorbased measurement technique started early. In the mid1950s, Clark et al. (1953) published their definitive paper on the oxygen electrode in an attempt to expand the range of analytes that could be measured in the human body. This electrochemical sensor has long since been adapted for oceanographic applications, and substantial improvements have been made. However, until today long-term calibration stability, temperature sensitivity, pressure hysteresis, susceptibility to biofouling, etc., have remained areas of concern that have essentially prohibited long-term deployments of oxygen sensors in the ocean.

The recent advent of a new optode-based oxygen sensor represents a major improvement of our oxygen measurement capabilities in long-term subsurface applications (A. Tengberg et al. 2004, manuscript submitted to Limnol. Oceanogr., hereafter TENG). The unique characteristics of this new oceanographic sensor make it suitable for adaptation to the present generation of profiling (and drifting) floats. Since the early times (Davis et al. 1992), profiling floats have become 
extremely valuable oceanographic tools and are presently being deployed in large quantities $(\sim 1500$ floats operational in December 2004) within Argo, a broadscale global array of temperature/salinity profiling floats. Lacking sensors of suitable characteristics for float applications, marine biogeochemists have until now not been able to exploit this new ocean observing tool. Here we present first results from a pilot study with two profiling floats carrying the new oxygen sensors.

\section{Methods}

\section{a. Profiling float}

For this study the APEX-260 float [Webb Research Corporation (WRC) East Falmouth, Massachusetts], an autonomous drifting profiler used to measure subsurface currents and make profile measurements was used. It surfaces at programmed intervals for profile acquisition, data telemetry, and geolocation via Argos satellites. The float automatically adjusts buoyancy to follow an isobaric surface while drifting at a selected depth. The "park and profile" feature allows drift depths to be different from maximum profile depths. Standard sensors for temperature, pressure, and salinity are available.

Two APEX floats carrying an oxygen optode (model 3830, Aanderaa Instruments AS, Bergen, Norway) as well as the standard CTD sensor (model 41, Sea-Bird Electronics, Inc., Bellevue, Washington) were used. All sensors were mounted on the upper endcap. The oxygen sensor returns oxygen concentration $(\mu \mathrm{M}=\mu \mathrm{mol}$ $\left.\mathrm{dm}^{-3}\right)$ and optode temperature $\left(T_{\text {opt }}\right)$ in addition to the pressure $(p)$, temperature $\left(T_{\mathrm{CTD}}\right)$, and salinity $(S)$ measurements provided by the CTD sensor of the float. Data were transmitted in 28-bit Argos format using the "Multi-Satellite Service." The drift and profile pattern of the floats (Fig. 1) includes an 800-db drift depth, a

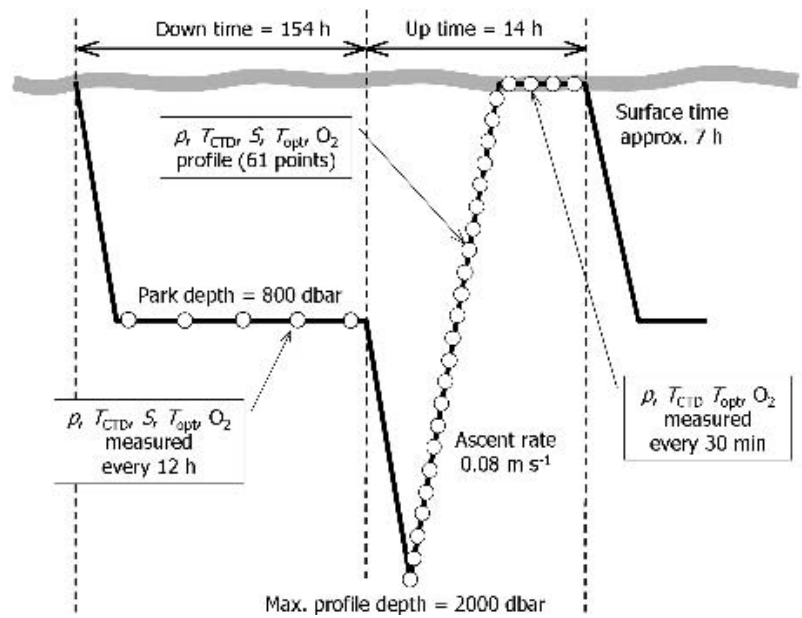

FIG. 1. Measurement and drift pattern of the two deployed prototype APEX profiling floats with oxygen optode sensors. maximum profile depth of $2000 \mathrm{db}$, and 61 data points per profile (WRC depth table 34, vertical resolution decreasing with depth from 10 to $50 \mathrm{db}$, shallowest sample at $4 \mathrm{db}$ ). In addition to the profile, CTD and optode measurements are performed every $12 \mathrm{~h}$ while drifting at park depth and half-hourly while at the surface (optode only).

\section{b. Oxygen optode}

The optode is based on a principle called dynamic luminescence quenching, which is the ability of a substance, in this case oxygen, to influence the fluorescence of a luminophore. After absorbing light of a certain energy, a luminophore will enter an excited state. Relaxation to the initial state involves internal energy dissipation through oscillation and emission of a photon of lower energy, that is, longer wavelength (fluorescence). An alternative relaxation mechanism is caused by energy transfer to a colliding molecule during which no photon is emitted. This nonemitting process is called dynamic quenching.

In the oxygen optode the luminophore, a platinum porphyrine complex, is immobilized in a sensing foil mounted on a sapphire optical window and exposed to the seawater. Ambient oxygen acts as the quenching agent. On the outside, the sensing foil is covered with a black gas-permeable coating to isolate it from light contamination in the photic zone. The luminophore is excited with a blue-green light $(505 \mathrm{~nm})$ from the inside and produces a red fluorescence that is measured by a photodiode through the same window. The gaspermeable foil equilibrates with the surrounding seawater. If oxygen is present, the red fluorescence will be quenched. The intensity of the returned light therefore depends on the amount of oxygen in the seawater. However, the fluorescence intensity is dependent on several other factors and therefore is not the optimal quantity for detecting oxygen. Instead the excitation light is modulated at $5 \mathrm{kHz}$, and the fluorescence lifetime, which is also affected by oxygen, is measured. While the principle has been known for quite a long time (Kautsky 1939), the technique has only fairly recently been introduced in aquatic research (Klimant et al. 1995). A detailed description of this and similar measuring principles has been given by Demas et al. (1999). The newly available optode-based oceanographic oxygen sensor has undergone a number of laboratory and field tests under variable conditions that demonstrate the performance of the sensor (TENG).

The optode has a number of advantages. 1) It comes factory calibrated and measures absolute concentrations without the need for repeated calibrations. 2) The pressure behavior is fully reversible and predictable. 3) As no oxygen is consumed, the measurement does not require stirring. 4) Sensitivity to biofouling is reduced, as no parts of the optical path are exposed to the seawater. 5) The fluorescence-lifetime-based measure- 
ment principle and luminophores aging properties suggest long-term stability.

The sensor is capable of measuring absolute oxygen concentrations with a resolution smaller than $1 \mu \mathrm{M}$ and an accuracy of less than $8 \mu \mathrm{M}$ (or $5 \%$, whichever is greater) across the concentration range $0-500 \mu \mathrm{M}$, that is, the full oceanic concentration range. With an $e$ folding (or $63 \%$ settling) time of less than $20 \mathrm{~s}$ the sensor is suitable for slow profiling. At the floats' typical ascent rate of $0.08 \mathrm{~m} \mathrm{~s}^{-1}$, the sensor will therefore develop a significant disequilibrium of more than $1 \mu \mathrm{M}$ only during passage of very sharp oxygen gradients of 1 $\mu \mathrm{M} \mathrm{m}{ }^{-1}\left[\right.$ or $\left.\sim 1.6 \mu \mathrm{M}(20 \mathrm{~s})^{-1}\right]$. For faster profiling applications the sensor could be equipped with foils without optical isolation. These foils give about a 4-times-shorter response times but are less robust and hence less suitable for long-term applications. In addition, there is evidence that the temperature equilibration of the sensor's titanium pressure housing may take longer. This could potentially lead to transient, not well-constrained temperature gradients in the optical measurements system that may cause slight deterioration of the overall accuracy (see the results section).

\section{First results}

The two APEX-optode prototypes were deployed in the Labrador Sea subpolar gyre on 7 September 2003 during the German R/V Meteor cruise 59/2. Both floats were deployed at the same time and in the same position $\left(56.55^{\circ} \mathrm{N}, 52.69^{\circ} \mathrm{W}\right)$, and the first three weekly profiles of both floats were obtained within distances of each other of 1.5-4.5 $\mathrm{n}$ mi. After that, the separation increased to about $30 \mathrm{n} \mathrm{mi}$, but the floats still followed very similar trajectories before they became more separated and decorrelated after around 2.5 months (distance increasing to more than $200 \mathrm{n} \mathrm{mi}$ ). Just short of 3 months in the field, float 2 developed a problem with the CTD's pressure sensor that had been detected and announced by S. Riser (School of Oceanography, University of Washington, Seattle, Washington) in August 2003. A recall of the floats for replacement of the CTD was issued immediately after that. Because of the tight deadline of the present pilot study, it was decided not to follow this recall, and the floats were deployed with the problematic pressure sensor that had shown a $\sim 10 \%$ failure rate during tests at the University of Washington.

The first profile taken simultaneously by both floats at a distance of about $1.5 \mathrm{n} \mathrm{mi}$ on 14 September shows a very good agreement between temperature, salinity, and oxygen (Fig. 2, only oxygen data shown). At depths greater than $800 \mathrm{db}$, temperature (mean offset 0.0005 , $\mathrm{rms}=0.007$ ) and salinity (mean offset 0.0009 , rms $=$ 0.0012 ) showed no systematic offset. Oxygen values systematically differed by $1.6 \mu \mathrm{M}$ across the $800-2000-\mathrm{db}$ depth range (Fig. 3) with an rms difference of $0.4 \mu \mathrm{M}$,

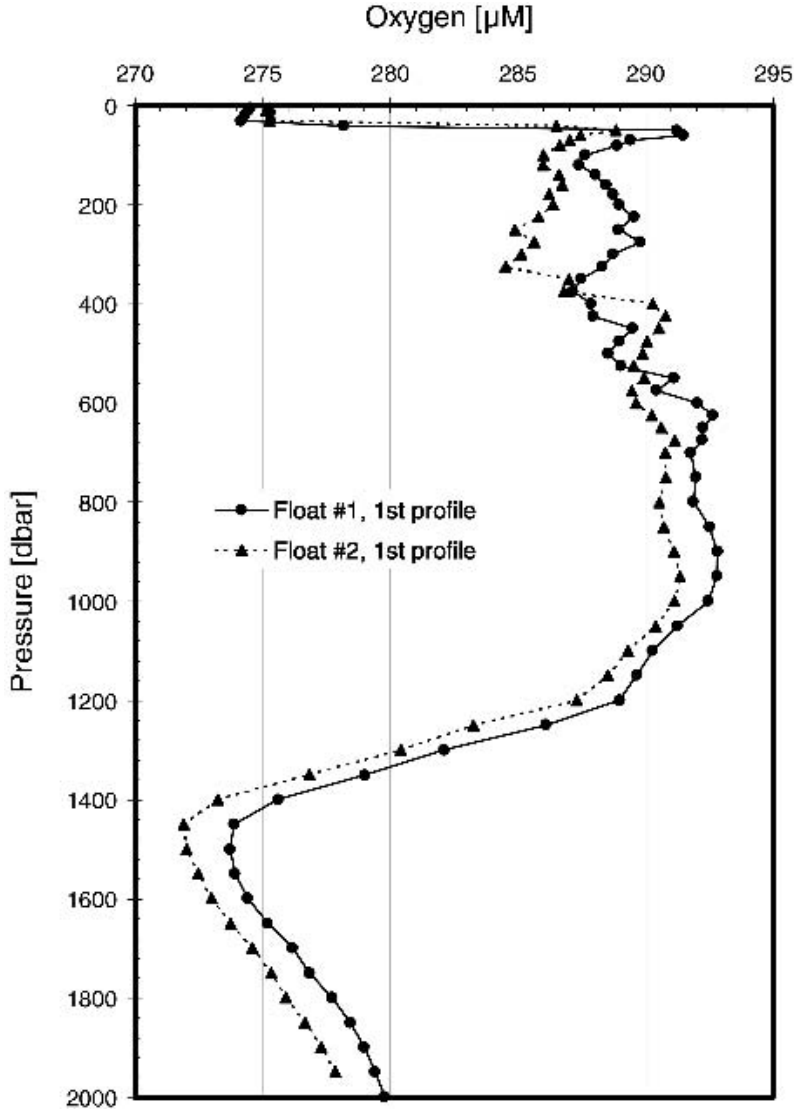

FIG. 2. First oxygen profiles obtained from the two floats on 14 Sep 2003 at $56.46^{\circ} \mathrm{N}, 53.02^{\circ} \mathrm{W}$ (distance $\sim 1.4 \mathrm{n} \mathrm{mi}$ ) in the Labrador Sea. Oxygen concentrations are pressure corrected and corrected to actual salinity.

which is well within the nominal accuracy of $8 \mu \mathrm{M}$. At depths shallower than $800 \mathrm{db}$, maximum differences of $0.018^{\circ} \mathrm{C}$ in temperature and 0.134 in salinity show that to some extent different water mass characteristics are represented in the two profiles, which can also be seen in higher variability of the oxygen residuals (Fig. 3). At the surface, oxygen residuals become very small $(\sim 0.8$ $\mu \mathrm{M})$ and change sign. This is not due to the effect of differences in sea surface temperature and salinity on equilibrium oxygen concentrations, which account for only $0.3 \mu \mathrm{M}$ of the shift in residuals. It therefore must reflect differences in the local saturation levels of the mixed layer.

The optodes' raw oxygen readings have to be corrected for pressure and salinity. The pressure effect is linear and fully reversible and causes readings to drop by $4 \%(1000 \mathrm{db})^{-1}$. The need for a salinity correction is due to the fact that the optode senses the partial pressure (strictly the fugacity) of oxygen in the water but does not "see" the salinity and hence reports values as if immersed in freshwater. Since the partial pressure of any gas is salinity dependent, the calculated oxygen concentration has to be corrected to the actual salinity. 


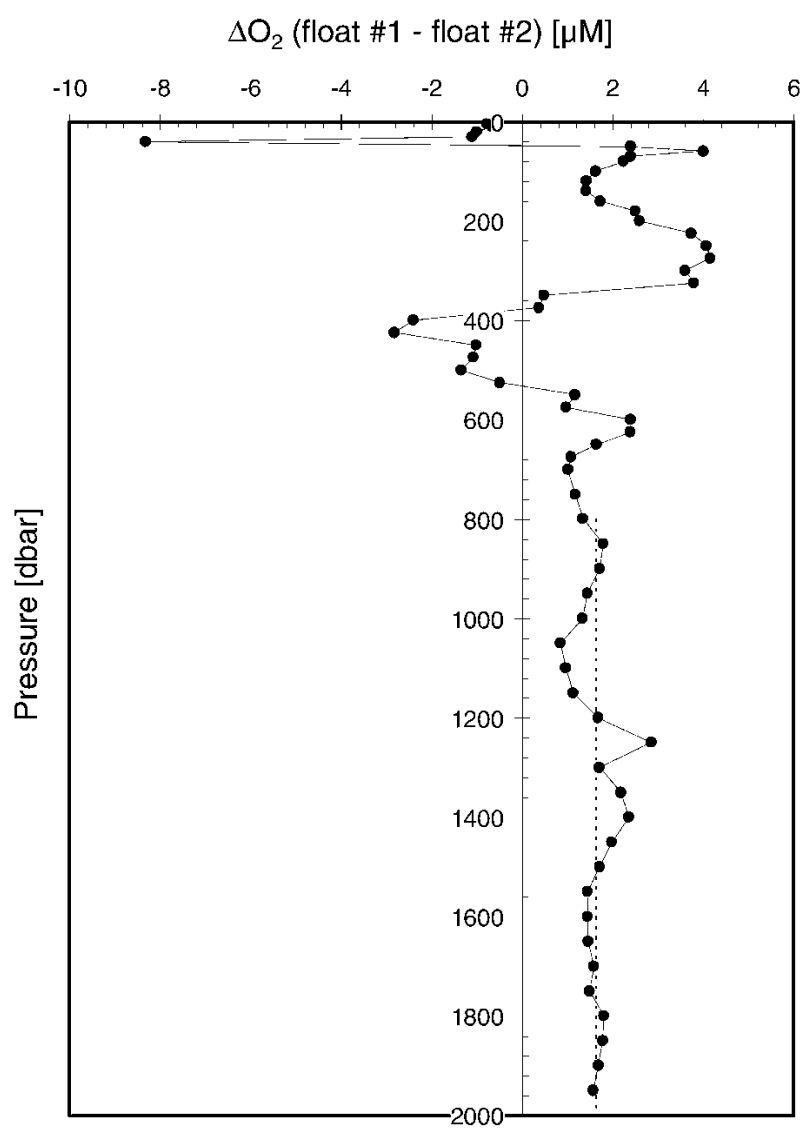

FIG. 3. Differences in (pressure and salinity corrected) oxygen concentrations between individual measurements obtained in parallel during the first profile of each float (i.e., difference of the profiles of Fig. 2).

We compared the first three oxygen profiles with oxygen concentrations measured by modified Winkler titration (Hansen 1999) on discrete samples from hydrocasts taken on 3-6 September 2003 within $50 \mathrm{n}$ mi of the float positions. The float and Winkler oxygen profiles are of almost identical shape but show an average offset of $-17.5 \pm 2.0 \mu \mathrm{M}$. This is well outside the nominal accuracy range of the optodes. Furthermore, several laboratory and field tests under very variable conditions have consistently shown that the sensor accuracy is typically well within the nominal accuracy of $8 \mu \mathrm{M}$ (TENG). For example, 1 month of optode measurements (1-min intervals) made in October/November 2002 (R/V Meteor cruise 55) by one of the authors (A.K.) on continuously pumped surface waters of the tropical Atlantic Ocean were in extremely good agreement with parallel Winkler titrations $(n=72$, offset $=$ $0.9 \mu \mathrm{M}, \mathrm{rms}=1.1 \mu \mathrm{M})$.

Together with the manufacturer and the Göteborg University, Sweden, which has been involved in the development and rigorous testing of the sensor, we found an explanation of this problem (A. Tengberg, Göteborg University, 2004, personal communication). Early pro- totypes of the sensor, such as the one used on the Meteor cruise 55, had been calibrated individually with a nonstandardized laboratory method. Apparently this method worked well and yielded high sensor accuracy. The first series of the commercial sensor, however, had been calibrated in a newly built calibration facility. This facility featured a seawater tank where air bubbling was introduced at a depth of $0.7 \mathrm{~m}$, and about 20 optode sensors were submerged at a level of $0.5 \mathrm{~m}$, that is, just above the air bubbling. In this early installation it had been overlooked that the hydrostatic pressure that is exerted on the air bubbled into the water increases the partial pressure of all gases contained by about $7 \%$ at the delivery point. While rising through the water column, this additional pressure decreases and finally disappears when the bubble reaches the surface. Additionally, a second pressure problem has been identified: the air conditioning in the constant-temperature room caused slight overpressure on the order of 10-20 mb.

When the calibration was performed, the outside air pressure was used in the calculations. The real pressure of equilibration, however, was higher by an estimated $6 \%$ due to the average hydrostatic pressure effect on the air bubbles as well as the calibration room overpressure. A sensor calibrated by using outside air pressure and assuming $100 \%$ oxygen saturation will therefore read oxygen concentrations that are typically low by $6 \%$. In the present case, one would expect our oxygen readings (mean of about $285 \mu \mathrm{M}$ ) to be low by about $17 \mu \mathrm{M}$, which almost exactly matches the observed offset of $-17.5 \pm 2.0 \mu \mathrm{M}$ between optode and Winkler data. The shortcomings in the factory calibration procedure are a very reasonable explanation for the observed offset, which was very similar between the two optodes and had also been reported by other customers who bought first series optodes. It should be noted that the manufacturer has improved the current calibration procedure to eliminate this problem. To remove the offset in the factory calibration in our case, we used the Winkler oxygen samples $(n=42)$ to "calibrate" the optodes such that the mean oxygen residuals (optode - Winkler) became zero (Fig. 4). This procedure was performed separately for the two optodes in order to remove the systematic offset of $1.6 \mu \mathrm{M}$ between them.

Temperature measurements made in parallel by the CTD and the optode's temperature sensor are in good agreement. The observed systematic offset of $0.03^{\circ} \mathrm{C}$ (for $p>300 \mathrm{db}$ ) is probably entirely due to the optode's thermistor, which does not achieve the high accuracy of a CTD sensor. However, the optode's temperature sensor develops a marked negative offset of up to $-0.8^{\circ} \mathrm{C}$ ( $\left.T_{\text {optode }}-T_{\text {CTD }}\right)$ when ascending through strong gradients of increasing temperature (Fig. 5). This results from the significantly larger time constant, which is a consequence of the sensor design with the thermistor being attached through thermal conductivity paste to the inner wall of the sensor's titanium pressure housing. 


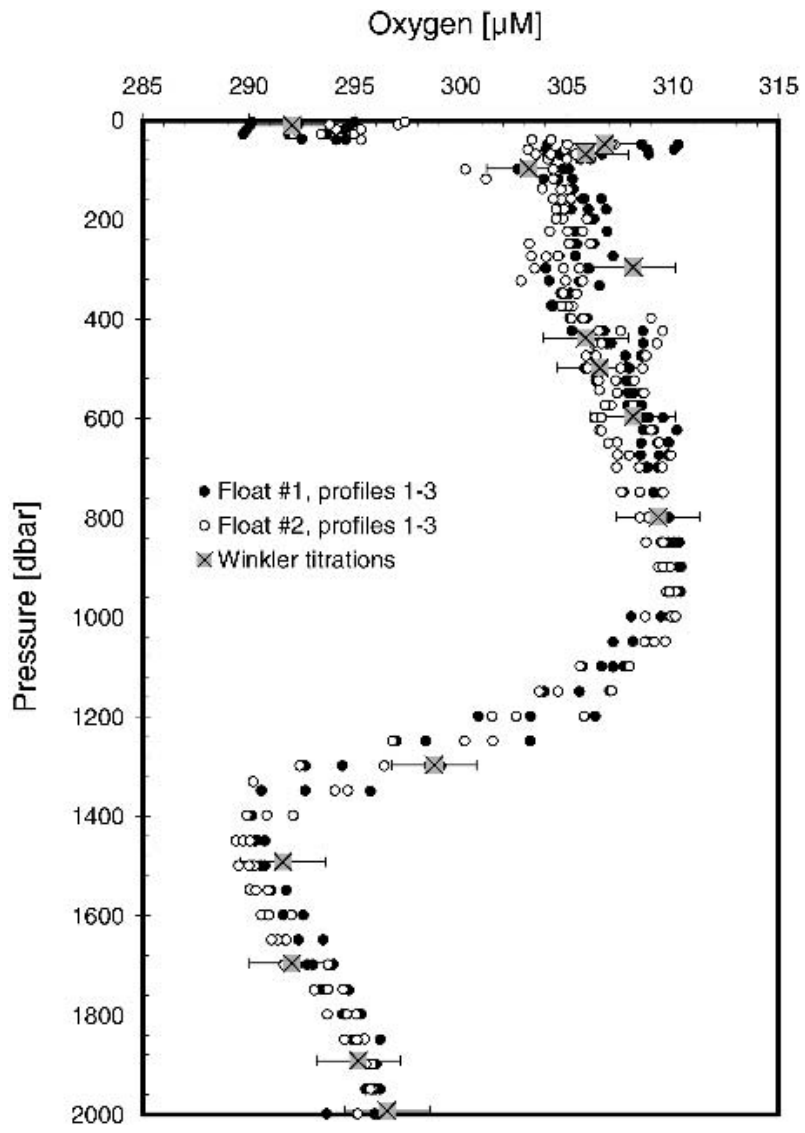

FIG. 4. "Calibration" of the first three oxygen profiles from both floats with Winkler oxygen data from discrete samples taken at nearby hydrocasts. The procedure removes the offset due to an inadequate factory calibration of the early sensors.

Therefore, it seems possible that during passage through steep temperature gradients the optode's temperature sensor (which is installed in the sensorfoot) does actually sense a temperature that is not identical to the measurement temperature of the sensing foil. The encountered temperature gradients of a few tenths of a degree per decibar are rather extreme cases, but the potential bias of the oxygen measurements under such conditions needs to be addressed further. It may be advisable to slow down the float's rise through depths of extreme vertical temperature gradients in order to avoid strong thermal disequilibria in the optode sensor. Another option would be to transmit the optode's "raw data" (phase shift) in parallel with the temperature readings from the fast-response CTD temperature sensors. The mathematical conversion to absolute oxygen readings could then be done either internally in the float or by postprocessing of the transmitted data.

The purpose of this paper is to introduce the novel approach of optode-based oxygen measurements from profiling floats. The first 28 oxygen profiles (Fig. 6) acquired since 7 September 2003 in the central gyre of the Labrador Sea may serve as an illustration of its scientific potential (see also Körtzinger et al. 2004). Cooling and deepening of the mixed layer are beautifully depicted in the temporal development of the surface ocean oxygen budget, which shows a very large inventory increase. In contrast to the strong "breathing" of the quickly deepening mixed layer with a clear change from super- to undersaturation, sharp oxygen "node points" with a minimum data scatter of about 2 $\mu \mathrm{M}$ and no temporal trends are found at $850 \mathrm{db}$ (excluding the 28th profile on 21 March) and $1800 \mathrm{db}$ (arrows in Fig. 6). These node points are associated with waters that appear to experience very little temporal change (variability $\sim 0.1^{\circ} \mathrm{C}$ in $T$ and $\sim 0.01$ in $S$ ) and are thus indicative of negligible sensor drift after almost 6 months in the field. Water masses at $1800 \mathrm{db}$ represent a blend of waters of northern origin that show significant changes on decadal and subdecadal time scales (Dickson et al. 2002; Curry et al. 2003) but do not exhibit trends on the time scale of several months. Oxygen conditions at $800 \mathrm{db}$ are affected on an annual basis by the intensity of deep convection during winter. The lack of seasonal trends at this depth is indicative of very small (in the context of a monthly time scale) oxygen utilization rates.

Since the sensor responds to the oxygen partial pressure, it is also capable of measuring in air. Therefore, oxygen measurements taken in air while the float is at the surface can potentially be used for drift control. Provided equilibrium with ambient air is achieved, the sensor reading should equal the oxygen concentration of freshwater in equilibrium with air (at ambient atmospheric temperature and pressure, $100 \%$ humidity, and an oxygen volume mixing ratio of 0.2095 ). In reality, however, the air around the sensors may not always be at $100 \%$ humidity. Furthermore, rough seas may cause the sensor to be wetted from spray or even get submerged in the water, which would hinder establishment of equilibrium with the ambient air. Similarly, warming of the black optical window by insolation may cause thermal disequilibrium. Despite these factors, which should lead to larger scatter and/or occasional offsets, actual sensor readings taken in air can be usefully compared with equilibrium concentrations calculated using ambient barometric pressure. We used 6-hourly mean sea level pressure [National Centers for Environmental Prediction (NCEP)-National Center for Atmospheric Research (NCAR) reanalysis; http://www.nomad2. ncep.noaa.gov/ncep_data/) to calculate the expected oxygen values for all surface measurements taken between 14 September 2003 and 22 February 2004 (Fig. 7). Given the uncertainty associated with possibly incomplete equilibration as well as the reanalysis pressure, the two datasets are in very favorable agreement (mean offset $0.3 \mu \mathrm{M}, \mathrm{rms}=7.6 \mu \mathrm{M}$ ). Atmospheric measurements thus provide for an easy means of longterm drift checks. 


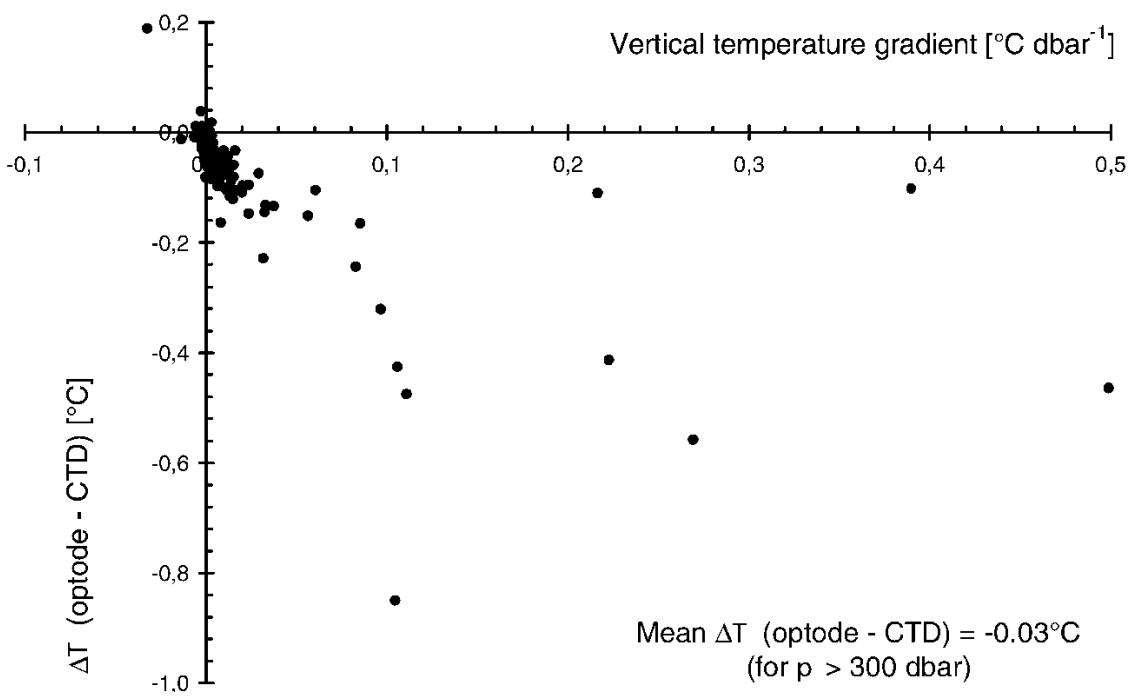

FIG. 5. Plot of temperature difference between optode and CTD temperature sensors vs vertical temperature gradient.

\section{Conclusions}

The newly available optode-based oxygen sensor features a number of innovative improvements (TENG) that make it suitable for long-term in situ deployment on autonomous observing platforms. Due to its small size and power requirement $(<40 \mu \mathrm{Ah}$ per measurement), it lends itself for installation on profiling floats.

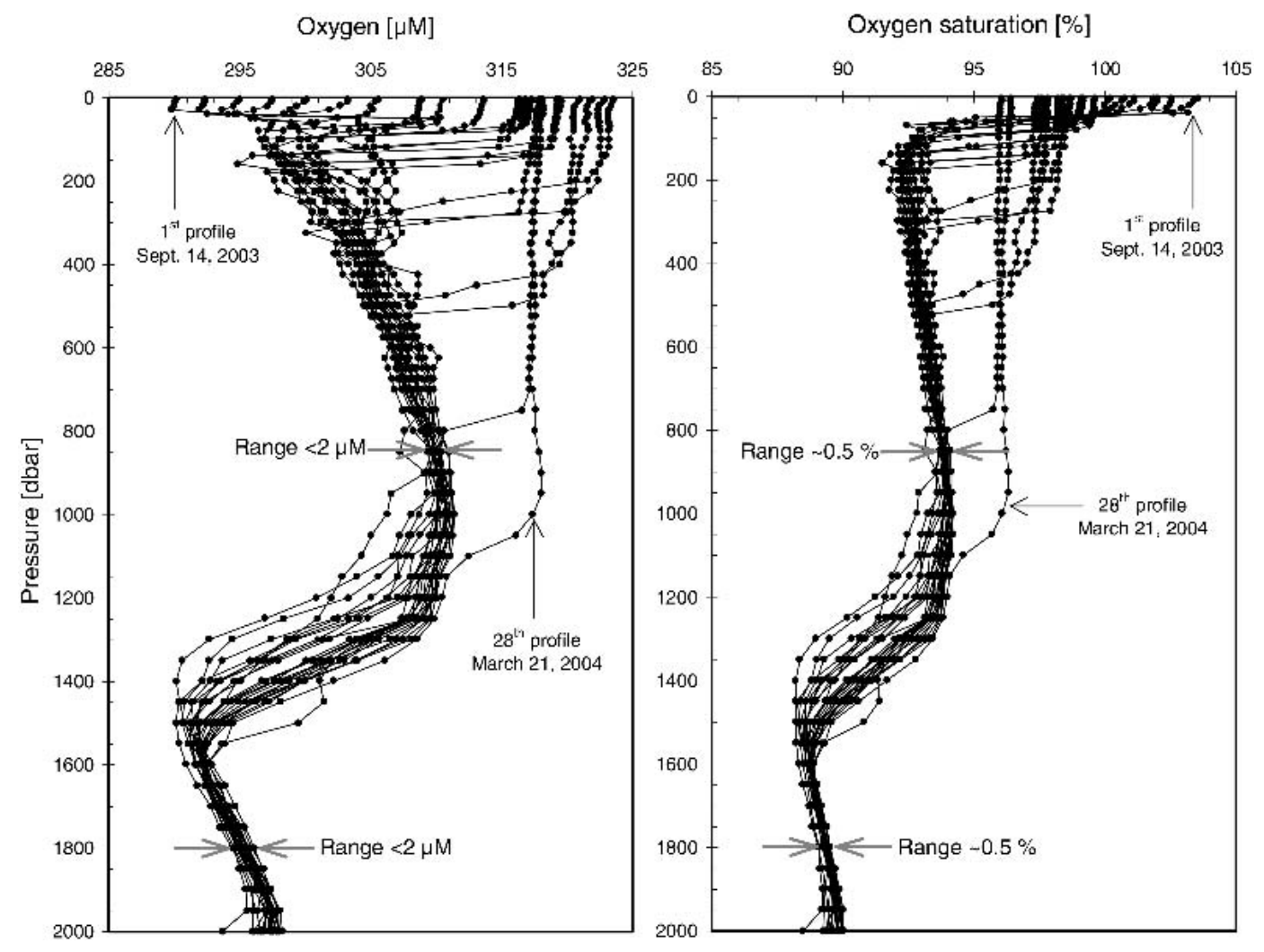

Fig. 6. First 28 calibrated profiles of (left) oxygen and (right) oxygen saturation obtained from the Labrador Sea illustrating quality and resolution as well as utility of this new approach for oxygen measurements in the ocean. 


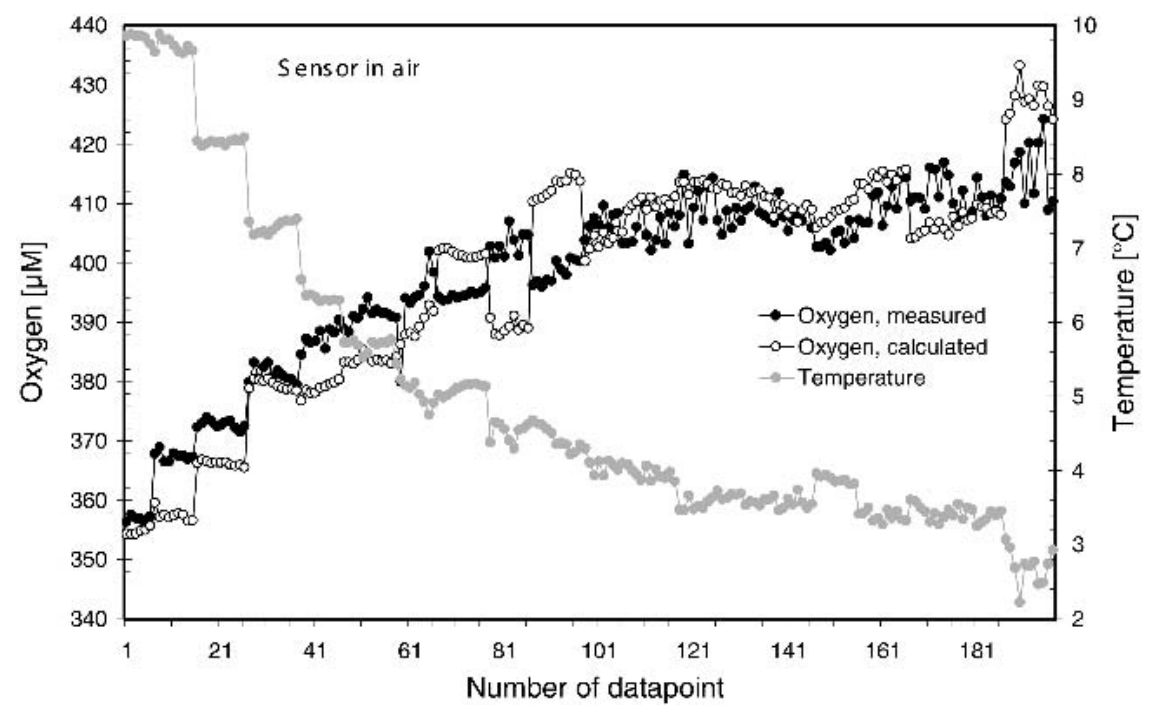

FIG. 7. Sensor readings of atmospheric oxygen and temperature between 14 Sep 2003 and $22 \mathrm{Feb} 2004$. Note that when measuring in moist air, the values correspond to freshwater oxygen concentrations in equilibrium with air (at atmospheric pressure, $100 \%$ humidity, and a oxygen volume mixing ratio of 0.2095 ).

The first results shown here demonstrate that high quality long-term oxygen measurements from floats are feasible. Although minor improvements (e.g., ascent speed) of the float-based measurements approach are possible, the method appears to be operational and can be used readily. Although the cause of the observed bias in our optode measurements has been identified in an inadequate factory calibration that has been fixed, a recommended practice would be to regularly perform a small hydrographic survey with Winkler oxygen measurements around the float deployment area. Such a deployment survey provides a straightforward means of quality control and the most precise calibration of the oxygen sensor. This should be routinely used to improve the sensor's accuracy to better than the $8-\mu \mathrm{M}$ nominal accuracy. Although the sensor has potentially good long-term stability, its ability to measure in air also provides a means for identification of any drift problem. For this additional purpose the sensor should be top mounted on the float.

Acknowledgments. Financial support of this study was granted by the DFG through the SFB 460 .

\section{REFERENCES}

Bopp, L., C. LeQuéré, M. Heimann, A. C. Manning, and P. Monfray, 2002: Climate-induced oceanic oxygen fluxes: Implications for the contemporary carbon budget. Global Biogeochem. Cycles, 16, doi:10.10292001GB001445.

Clark, L. C., R. Wolf, D. Granger, and Z. Taylor, 1953: Continuous recording of blood oxygen tensions by polarography. $J$. Appl. Physiol., 6, 189-193.
Curry, R., B. Dickson, and I. Yashayaev, 2003: A change in the freshwater balance of the Atlantic Ocean over the past four decades. Nature, 426, 826-829.

Davis, R. E., D. C. Webb, L. A. Regier, and J. Dufour, 1992: The Autonomous Lagrangian Circulation Explorer (ALACE). $J$. Atmos. Oceanic Technol., 9, 264-285.

Demas, J. N., B. A. De Graff, and P. Coleman, 1999: Oxygen sensors based on luminescence quenching. Analyt. Chem., 71, 793A-800A.

Dickson, B., I. Yashayaev, J. Meincke, B. Turrell, S. Dye, and J. Holfort, 2002: Rapid freshening of the deep North Atlantic Ocean over the past four decades. Nature, 416, 832-837.

Hansen, H. P., 1999: Determination of oxygen. Methods of Seawater Analysis, K. Grasshoff, K. Kremling, and M. Ehrhardt, Eds., Verlag Chemie, 75-89.

Joos, F., G.-K. Plattner, T. F. Stocker, A. Körtzinger, and D. W. R. Wallace, 2003: Trends in marine dissolved oxygen: Implications for ocean circulation changes and the carbon budget. Eos Trans. Amer. Geophys. Union, 84, 197-204.

Kautsky, H., 1939: Quenching of luminescence by oxygen. Trans. Faraday Soc., 35, 216-219.

Keeling, R. F., and H. Garcia, 2002: The change in oceanic $\mathrm{O}_{2}$ inventory associated with recent global warming. Proc. U.S. Natl. Acad. Sci., 99, 7848-7853.

Klimant, I., V. Meyer, and M. Kohls, 1995: Fibre-optic oxygen microsensors: A new tool in aquatic biology. Limnol. Oceanogr., 40, 1159-1165.

Körtzinger, A., J. Schimanski, U. Send, and D. W. R. Wallace, 2004: The ocean takes a deep breath. Science, 306, 1337.

Levitus, S., J. Antonov, T. Boyer, and C. Stephens, 2000: Warming of the World Ocean. Science, 287, 2225-2229.

Matear, R. J., A. C. Hirst, and B. I. McNeil, 2000: Changes in dissolved oxygen in the Southern Ocean with climate change. Geochem. Geophys. Geosyst., 1, doi:2000GC000086.

Winkler, L. W., 1888: The determination of dissolved oxygen. Ber. Dtsch. Chem. Ges., 21, 2843-2846. 